\title{
Harmonic Distortion Evaluation Generated by PWM Motor Drives in Electrical Industrial Systems
}

\author{
Vladimir Sousa ${ }^{1}$, Hernán Hernández Herrera ${ }^{2}$, Enrique C Quispe ${ }^{3}$, Percy R Viego ${ }^{4}$, Julio R Gómez ${ }^{5}$ \\ ${ }^{1,2}$ Electrical Engineering Department, Corporación Universidad de la Costa, Calle 58 No.55-66, Barranquilla, Colombia \\ ${ }^{3}$ Energy and Mechanical Department, Universidad Autónoma de Occidente, Calle 25 No.115-85, Barranquilla, Colombia \\ ${ }^{4,5}$ Center of Energy and Environmental Studies Department, Universidad de Cienfuegos, \\ Carretera a Rodas Km 4 Cuatro Caminos, Cienfuegos, Cuba
}

\begin{tabular}{l}
\hline \hline Article Info \\
\hline Article history: \\
Received Jan 19, 2017 \\
Revised Jun 19, 2017 \\
Accepted Jul 9, 2017 \\
\hline
\end{tabular}

Keyword:

Electrical industrial system

Harmonic distortion

PWM motor drives

Harmonic statistical annalysis

\begin{abstract}
This paper evaluates the harmonic distortion generated by PWM motor drives in an electrical industrial system of a wheat flour mill company. For this, a comparative study between two industrial circuits connected at the same point of common coupling (PCC) with similar characteristics of load and transformers is presented. The difference is that one circuit has PWM motor drives and the other does not have them. In the study, a practical method based on the statistical characterization of the total harmonic distortion of voltage (THDV) and current (THDI), individual voltage distortion (IVD), individual current distortion (ICD) and K-Factor is applied. As result, it was observed that PWM motor drives generated voltage harmonics mainly of fifth and seventh order with values that exceed limits established by standards in both circuits. With these values, the operation of elements such as capacitors, motors and transformers can be affected. In the work is also demonstrated that in the analysis of harmonics is necessary to consider various parameters and not only one.
\end{abstract}

Copyright $\left({ }_{0} 2017\right.$ Institute of Advanced Engineering and Science. All rights reserved.

\section{Corresponding Author:}

Hernan Hernández Herrera, Electrical Engineering Department, Corporación Universidad de la Costa, Calle 58 No.55-66, Barranquilla, Colombia.

Email: hhernand16@cuc.edu.co

\section{INTRODUCTION}

The problems associated with power system harmonics are reflected in the increase in the use of non-linear loads in new technologies. It is estimated that more than 50\% of the European and US loads will contain power electronics in the near future [1]. In industry, there is a widespread use of motors supplies from several types of solid-state adjustable voltage-frequency controllers (VSDs) [2]. Among these, the pulse width modulation (PWM) motor drives are the most common used because of several advantages compared to various other VSDs [3]. High reliability, robustness, low cost, an efficient and fast induction motors control in many automated industrial applications and the possibility of saving up to $60 \%$ of energy, are the main reasons for the extensive use of PWM motor drives [4]-[6]. However, the operation principle of PWM motor drives and its electronic composition, produce distortion on voltage and current waves with abundant high-frequency harmonics [7].

Harmonic voltages increase magnetic core losses in motors and transformers, while harmonics current increase losses in winding and structure of most of the components of electrical systems. These losses cause temperature rise and life-span reduction [8]. Some investigations have studied the effects of harmonics produced by PWM motor drives or by others non-linear devices on electrical industrial systems elements, focusing on motors, transformers and capacitor banks. 
In [2], is observed that the PWM inverter could increase the copper losses of motors in more than $50 \%$. In [1],[9], a curve of reduction of motor life as a function of harmonics of fifth order, shows that motor life expectancy begins to reduce from an individual voltage distortion (IVD) value of $3 \%$. In [10], the operating temperature of a motor of $1.5 \mathrm{~kW}$ increased in $6.8 \%$ and a possible reduction in the lifetime of $44.5 \%$ is observed, when is supplied from a three-phase bridge type thyristor inverter.

Some studies demonstrate that the harmonics of fifth and seventh order are the most harmful for motor operation [11],[12]. In [11], a $100 \mathrm{hp}$ motor supplies with $6 \%$ of IVD of fifth-order harmonic, reduced its motor life in $18 \%$. In [12], is demonstrated that the efficiency is reduced by $3 \%$, in a $1.5 \mathrm{~kW}$ motor operating in the presence of harmonics of fifth and seventh order. Harmonics also have significant effects on the oscillations frequency of torque and vibrations [13]. Studies demonstrate that with typical values of harmonic distortion combined with the maximum levels of voltage unbalance allowed by [14], are sufficient to introduce vibrations levels under which continuous operation of the induction motor is not recommended [13].

The discharging bearing current is an important effect caused by PWM drivers in motors [15],[16]. This phenomenon, produced by the common mode voltage of PWM inverter, causes increase friction between the races and rolls and damage of bearing in a short time. Other studies show that inadequate programming of amplitude modulation ratio (M) and switching frequency (fc) of PWM drivers, increases significantly the eddy current losses of motors, reducing its efficiency [17],[18]. Losses and life expectancy in transformers depend on the level of harmonics and the transformer load [19]. In [8], is observed that core losses could be increased up to $15 \%$ in a three-phase distribution transformer, due to effects of higher-order harmonics current produced by nonlinear domestic loads.

The K-Factor is a parameter used for analysis of the effects of harmonics current on transformer losses and the reduction in the life expectative [20]-[22]. By using K-Factor can be calculated the additional heating in transformer windings associated with harmonic currents [20]. The K-Factor is used in [21] for studying the potential reduction of transformer life-span. For a $25 \mathrm{kVA}$ pole-type oil-immersed distribution transformer, working with (K-Factor=12), relative temperature increases in $6.6^{\circ} \mathrm{C}$ in the transformer core. In [22] is analysed the influence of harmonics generated by adjustable-speed drives in the design and application of transformers.

The principal effects on capacitors working in the presence of harmonics are the premature breakdown of dielectrics, temperature rise and rustling of capacitors bank [23],[24]. In [23], is show that each harmonic order affects in a different way to capacitor dielectric, among these, third-order harmonics is the most harmful [23]. The failure of the dielectric on low voltage power capacitors due to harmonic resonance effects is analysed in [24]. The study carried out on 25 banks of capacitors showed that harmonics with THD voltage higher than $5 \%$ caused that $56 \%$ of the banks had a useful life only up to 4 months [24].

Due to the issues discussed, the evaluation of power quality in electrical industrial systems is important to identify the presence of high levels of harmonics and take actions to reduce its effects on motors, capacitors, transformers and others devices [25]. In [19], a study of energy quality in two-distribution transformers of two buildings in a University is carried out. In [8], the power quality in a distribution transformer that feeds a residential power grid is analysed. In [26], the quality of the energy and the harmonics in an electrical circuit with personal computers are characterized. The impact of sugar centrifugal process on power quality of a sugar industry electrical grid is studied in [27]. The energy losses due to harmonics generated by nonlinear loads in residential, commercial and office loads are studied in [28].

Unlike the works discussed above, this paper evaluates the harmonic distortion generated by PWM motor drives and the impact on the power quality in an electrical industrial system of a wheat flour mill company. In Section II, the method, harmonic distortion parameters, statistical tools, and evaluation criteria used, are described. In Section III, results and discussions of evaluation of harmonics distortion generated by PWM motor drives in two industrial circuits are presented. Circuits have similar characteristics of load and transformers and are connected at the same point of common coupling (PCC). The difference is that one circuit has PWM motor drives and the other one does not include it.

\section{RESEARCH METHOD}

\subsection{Harmonic Distortion Parameters.}

The applied method is based on characterizing the harmonics generated by the PWM motor drives from the harmonic distortion parameters: total harmonic distortion of voltage (THDV), total harmonic distortion of current (THDI), individual voltage distortion (IVD), individual current distortion (ICD) and KFactor. The parameters THDV, THDI, IVD and ICD are defined in the IEEE Std-1159-2009 standard [14] as following:

IJECE Vol. 7, No. 6, December 2017 : 3207 - 3216 


$$
\begin{aligned}
& \text { THDV }=\sqrt{\frac{\sum_{\mathrm{k}=2}^{\infty} \mathrm{V}_{\mathrm{k}}^{2}}{\mathrm{~V}_{1}^{2}}} \cdot 100 \\
& \mathrm{THDI}=\sqrt{\frac{\sum_{\mathrm{k}=2}^{\infty} \mathrm{I}_{\mathrm{k}}^{2}}{\mathrm{I}_{1}^{2}}} \cdot 100 \\
& \mathrm{IVD}=\frac{\mathrm{V}_{\mathrm{k}}}{\mathrm{V}_{1}} \cdot 100 \\
& \mathrm{ICD}=\frac{\mathrm{I}_{\mathrm{k}}}{\mathrm{I}_{1}} \cdot 100
\end{aligned}
$$

Where, the subscript $\mathrm{k}$ represents harmonics order and subscript 1 represents fundamental component. In $69 \mathrm{kV}$ and below, with the ratio among the maximum short-circuits current (Isc) and the maximum demand load current (IL) between 100 and 1000 at PCC; the limits of THDV, THDI, IVD and ICD are observed in Table 1 [14].

Table 1. Limits of THDV, THDI, IVD and ICD

\begin{tabular}{cc}
\hline Parameter & Limits (\%) \\
\hline THDV & 5 \\
THDI & 15 \\
IVD & 3 \\
ICD & 12 \\
\hline
\end{tabular}

$\mathrm{K}$-Factor is a harmonic distortion parameter that considers the harmonics current effect on transformer losses and it is defined as [24]:

$$
\mathrm{K}-\text { Factor }=\sum_{\mathrm{k}=1}^{\infty}\left(\frac{\mathrm{I}_{\mathrm{k}}}{\mathrm{I}_{1}}\right)^{2} \cdot \mathrm{k}^{2}
$$

The additional heating due to the square of the per unit harmonic load currents and the square of the harmonic order is the characteristic that dominates premature breakdown of transformers supplying nonsinusoidal currents, due to abnormal winding temperature rise [21]. Because the K-Factor considers frequency, it is the most accurate and the most useful method to estimate nonlinear load harmonic content for the specification of dry-type power distribution transformers [22].

\subsection{Statistical Tools for Harmonics Analysis}

Field measurements indicate that voltage and harmonics current are time-variant due to continuous changes in system load conditions [14]. Variations often occur rapidly in a non-deterministic or random form, so is necessary to use statistical tools to quantify harmonics level [29]. The average value, the probability distribution function and the correlation between THDV and THDI, are statistical tools used in the applied method.

Average value of THDV, THDI, IVD, ICD and K-Factor, are a reference to compare the level of harmonics between areas and with standards limits [20],[14]. Because of the variation in harmonics behaviour, the average value is not enough, so the use of probability distribution function is recommended [29]. The probability distribution function gives the summation of all the intervals in which the variable exceeds a certain level, e.g. the limit set by standards [29]. This tool can be applied with the help of the graphical user interface "dfittool" of Matlab. The correlation between THDV and THDI allows analysing both, the influence of harmonics current generated by nonlinear loads on the voltage waveform of feeders and the influence of distorted voltage waveform on the current waveform in circuits [29]. 


\subsection{Method}

The steps of the applied method for the evaluation of harmonic distortion generated by PWM motor drives on electrical industrial system are:

1. Selecting of two areas fed from two transformers with equal properties connected to the same point of common coupling (PCC). Areas have motors with similar features and operating regime. In one of the area, motors use PWM motor drives, while in the other area does not have PWM.

2. Measurement with power quality analyser from the secondary of transformer, the electrical parameters, mainly the following harmonic distortion parameters: THDV, THDI, IVD, ICD and K-Factor.The recommended monitoring period is defined as a complete working cycle [14].

3. Statistical analysis of the behaviour of THDV, THDI, IVD, ICD and K-Factor.

4. Evaluation of the harmonic distortion parameters considering standard [14].

\section{RESULTS AND ANALYSIS}

\subsection{Case Study}

The effects of harmonics generated by PWM motor drives were studied in two areas of a wheat flour mill company. In both areas, all the milling process is carried out. Two equal independent dry-type power distribution transformers of $1500 \mathrm{kVA}$ supply energy to both areas. The two circuits are close to each other and are connected to the same PCC. The total load of each area is similar, with $1203 \mathrm{~kW}$ of installed power, and 130 induction motors from $0.18 \mathrm{~kW}$ to $110 \mathrm{~kW}$ each one. The main differences in both areas are following:

- In Area A, there are 50 PWM motor drives of six and twelve pulses with a total capacity of $159.6 \mathrm{~kW}$ installed in the main motors of the milling process. Each mill receives the feedstock from a PWM motor drive system of $0.75 \mathrm{~kW}$. In addition, there is a turbine-motor of $110 \mathrm{~kW}$, fed by a PWM motor drive. Others small motors employ PWM motor drives. Table 2 shows the general characteristics of the PWM motor drives.

- In Area B, PWM motor drives are not used. The mills receive the feedstock from a mechanical drive. The turbine-motor of $110 \mathrm{~kW}$ and other small motors are fed directly from the network.

Table 2. Characteristics of PWM motor drives

\begin{tabular}{cccc}
\hline Quantity & Power $(\mathrm{kW})$ & Manufacturer & Pulses \\
\hline 1 & 110 & Siemens & 12 \\
24 & 0.75 & Allen-Bradley Power Flex & 6 \\
16 & 0.75 & Altivar- Schneider Electric & 6 \\
5 & 2.23 & Sew & 12 \\
4 & 2.1 & Power Flex 4M & 6 \\
Total & 159.6 & & \\
\hline
\end{tabular}

For the analysis, the electrical parameters were measured with two identical power quality and energy analysers Fluke 435 II. The instruments registered the electrical parameters at the same time during one week in the secondary of each transformer. Figure 1 shows the general electrical scheme of two areas. In Figure 1, Mm represents the mills motors, Mf the motors that supply the feedstock to mills and M represents the rest of motors including a turbine-motor. 


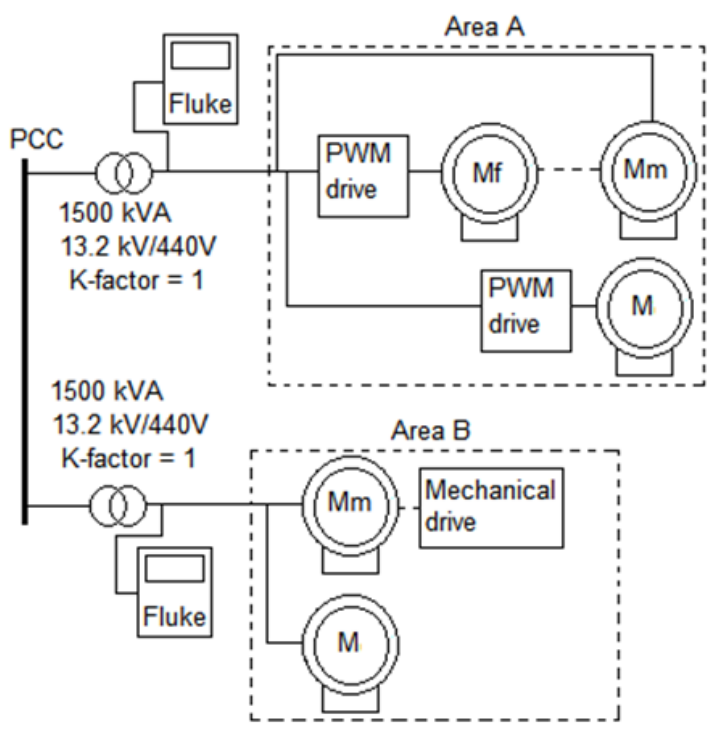

Figure 1. Scheme of two areas

\subsection{Behaviour of Harmonic Distortion Parameters}

Figure 2 shows the behaviour of THDI and THDV during the registered period in areas A and B. Figure 2 (a) shows that in the circuit with PWM motor drives connected (Area A), the THDI is greater than the circuit without PWM motor drives (Area B). The THDI values in Area A, exceed 15\%, the limit established by the IEEE Std 1159-2009 [14]. Figure 2 (b) shows that in both circuits the THDV has a variable behaviour around similar values. In both cases, the THDV is near and less than 5\%; only some points exceed this limit.

This demonstrates that distortion on the current waveform in a circuit is a direct consequence of PWM motor drives. In addition, the THDV caused by nonlinear loads in Area A, affects the circuits connected to the same feeder, such as in Area B, which does not have non-linear loads.

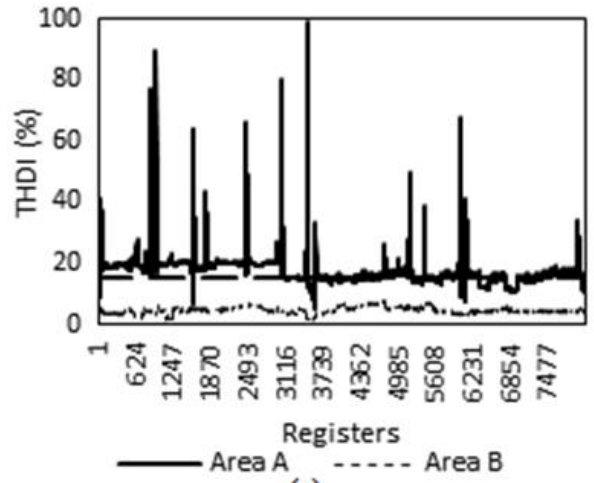

(a)

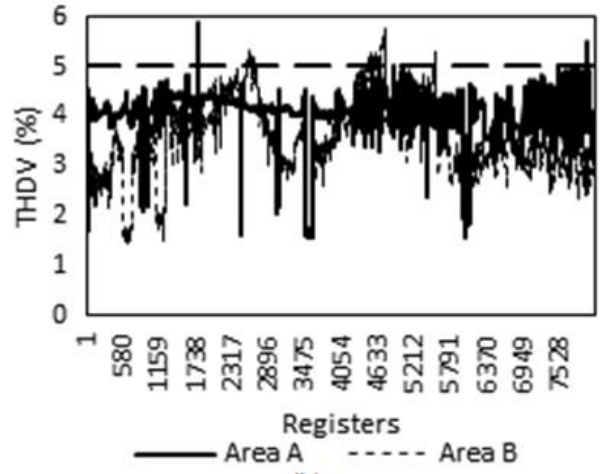

(b)

Figure 2. Variation of (a) THDI and (b) THDV in both areas

Figure 3 presents the graphs of probability distribution function corresponding to registers of THDI and THDV previously observed. In Figure 3 (a), probability distribution function allows specifying that in Area A, $81.74 \%$ of data are above $15 \%$, limit established by standard [14] for THDI. In Area B, all values of THDI are lower than 15\%. In Figure 3 (b) is observed that in Area B, only $4.56 \%$ of data exceeds the limit of 5\% set by [14] for THDV; in Area A, this value is not reached. Nevertheless, taken $4 \%$ as a reference of THDV, it is observed that in Area A, in general, the THDV is greater than in Area B throughout all period, although is below the limit of 5\%. It is important to note that although in Area A the THDV does not exceed the limits set by [14], the THDI generated by PWM motor drives has high values that exceed the stablished limits. 


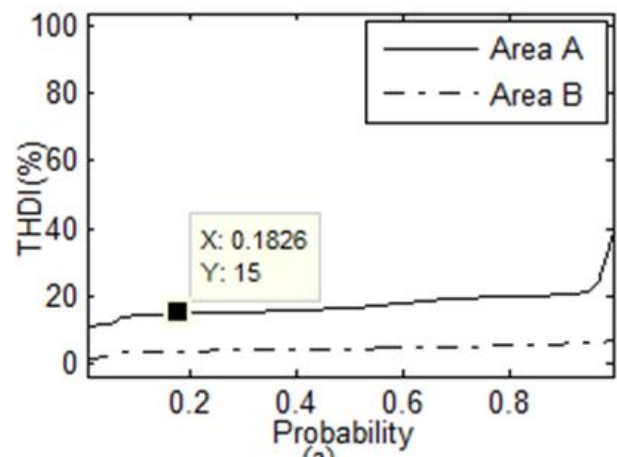

(a)

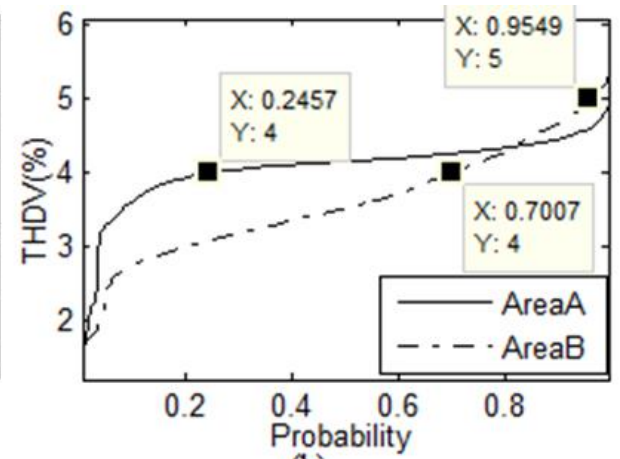

(b)

Figure 3. Probability distribution function of (a) THDI and (b) THDV in both areas

To determine the relationship between THDI and THDV, a scatter plot for each area with the corresponding linear fit was obtained. This is shown in Figure 4. In the circuit of Area A, the correlation coefficient is only 0.0236 , indicating that there is no simple relationship between THDI and THDV. This is because the THDI is caused by the combination of PWM motor drives of the circuit and the effect of THDV of network. In the circuit of Area B, the correlation coefficient is 0.8684 . In this circuit, there are not nonlinear elements; therefore, the high correlation indicates that the THDI is a direct consequence of THDV of the network due fundamentally to the current distortion generated by PWM motor drives of the circuit of Area A.

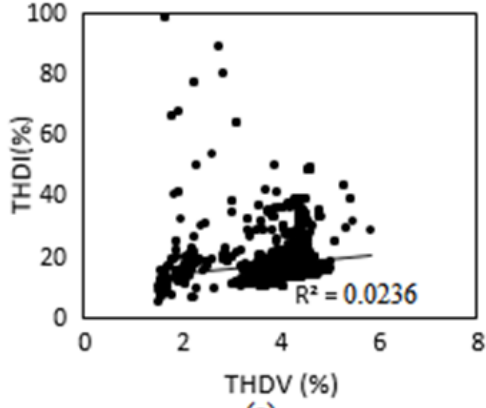

(a)

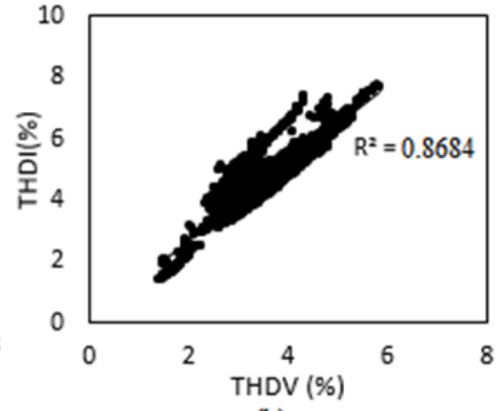

(b)

Figure 4. Scatter plot of THDI as function of THDV, (a) area A, (b) area B.

The analysis of the individual harmonics is important because each level of harmonic according to its sequence has a different impact on the elements and devices of electrical circuits [12],[14]. The average of measurements of IVD and ICD in both areas is presented in Figure 5 in bar graphs. In the circuit of Area A, because of the presence of PWM motor drives, the ICD of each harmonic level is higher than the circuit of Area B, where there are not PWM motor drives. In the circuit of Area A, the average of ICD of fifth-order harmonic exceeds the limit of $12 \%$ set by [14].

Concerning IVD, an affectation is observed in both circuits with harmonics of fifth and seventh order mainly. Voltage harmonics of fifth order in Area A, are higher to those in Area B, while in Area B, voltage harmonics of seventh order are higher to those in Area A. In Area B, the average of IVD of the seventh order exceeds the limit of $3 \%$ set by [14]. 


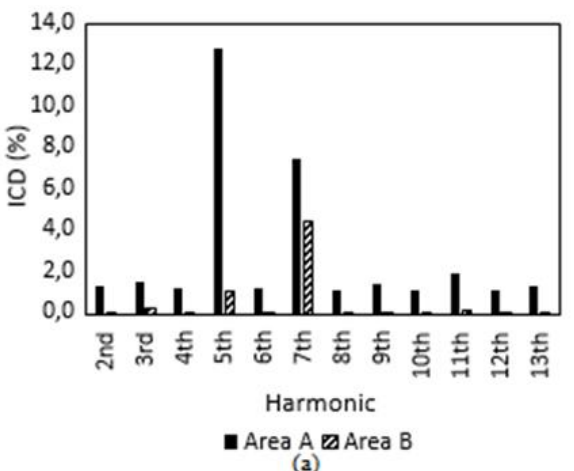

(a)

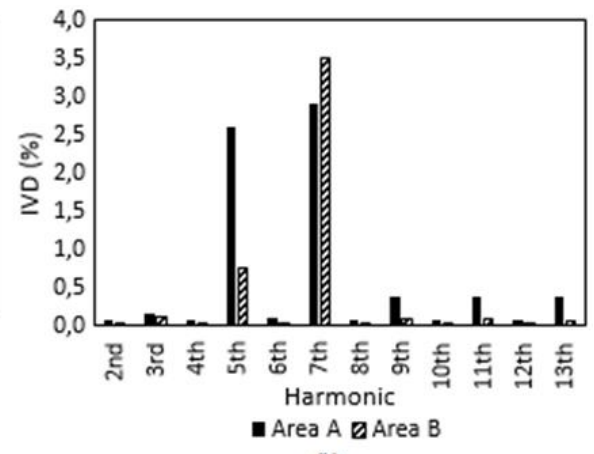

(b)

Figure 5. Average of ICD and IVD in both areas

The figure shows that in both circuits, there are current and voltage harmonics from second to thirteenth order. Nevertheless, theoretically, six-pulse converters should generate harmonics of $(6 \mathrm{k} \pm 1)$ order [14], therefore, should not be presented even harmonics or third-order harmonics. However, in [30],[31] it demonstrates that in some cases may appear new even and odd harmonics referred to as no-characteristic or atypical harmonics. This is due to several defects in inverters such as: asymmetry, inaccuracy in thyristor firing times and imperfect switching time and filtering [31]. To observing the behaviour of IVD and ICD of the most significant harmonics, Figure 6 shows the graphs of probability distribution function of harmonics of fifth and seventh order.

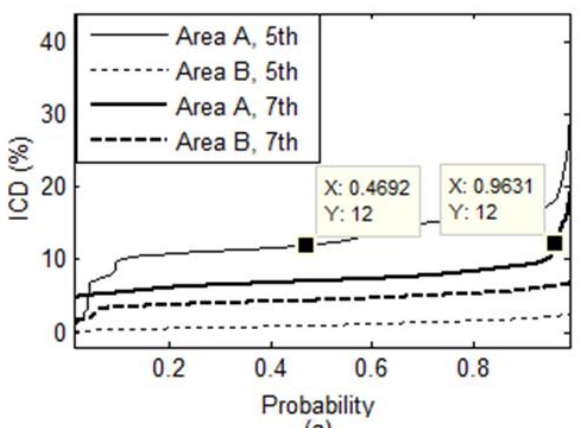

(a)

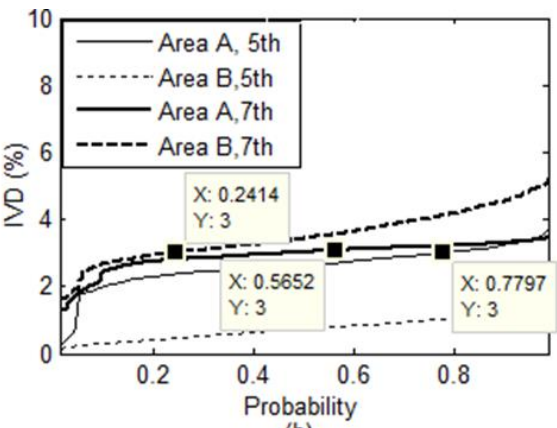

(b)

Figure 6. Probability distribution function of (a) ICD and (b) IVD in both areas

Figure 6 (a) confirms that ICD of fifth-order harmonics are the most significant and circulate in the circuit of Area A. The $53.08 \%$ of registers exceed the limit of $12 \%$ set by [14]. In the circuit of Area B, only $3.69 \%$ of ICD of seventh-order harmonics exceed the limit. In Figure 6 (b), is observed that IVD most significant are of fifth-order harmonics in the circuit of Area A, and seventh-order harmonics in both circuits. In Area A, $22.03 \%$ of data corresponding to fifth-order harmonics and $43.48 \%$ of data of IVD of seventhorder harmonics, exceed the limit of 3\% set by [14] for IVD. Area B is the most affected by harmonics of seventh order with $75.86 \%$ of the data exceeding the limit of the standard.

Is noteworthy that although the values of THD were below the limit of [14], the values of IVD exceed the corresponding established limit. Low-frequency harmonics of the fifth and seventh order generated by PWM motor drives are very harmful, because the impedance of the system for these harmonics is low, and facilitated the flow of harmonic currents. For that reason researches prioritizes the study based on low order harmonic [8],[9],[11],[12].

According to [23],[24], the values achieved of IVD and ICD in harmonics of fifth and seventh order generated by PWM motor drives, would be sufficient to cause resonance and multiplication of the harmonic currents and voltages affecting the capacitors. In [9],[11],[12] it is shown that with the behaviour of IVD in the two areas, losses and heating in motors is increased. Therefore, its efficiency and life expectative is reduced. The other parameter directly related to the effect of harmonic distortion on transformers is the KFactor. Figure 7 presents the K-Factor in the two areas and its comparison with the design value (KFactor $=1$ ) of used transformers. 


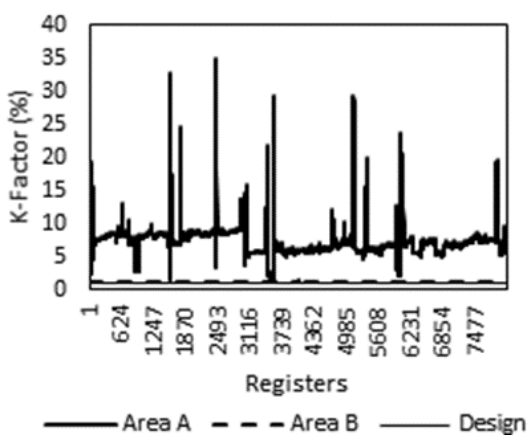

Figure 7. K-Factor in areas A and B

According to (5), the K-Factor depends directly on the harmonic current. For this reason, K-Factor in the transformer of Area A, is greater than in transformer of Area B. In transformer of Area B, K-Factor value is close to its design value; however, in the transformer of Area A, K-Factor values are about seven, well above of design value. This could cause an additional heating and reduction in life due to harmonics in this transformer [20]-[22].

\subsection{Summary of Results}

The average values of the parameters analysed are shown in Table 3. As can been observed, the parameters depending on voltage harmonics don't have a clear difference between areas. However, the parameters depending on current harmonics are greater in Area A.

Table 3. Harmonic distortion parameters

\begin{tabular}{|c|c|c|}
\hline Parameters & Area A & Area B \\
\hline THDV (\%) & 4.06 & 3.59 \\
\hline THDI (\%) & 17.72 & 4.67 \\
\hline $\operatorname{IVD} 5^{\text {th }}(\%)$ & 2.59 & 0.75 \\
\hline $\operatorname{IVD} 7^{\text {th }}(\%)$ & 2.91 & 3.49 \\
\hline $\operatorname{ICD} 5^{\text {th }}(\%)$ & 12.88 & 1.10 \\
\hline $\operatorname{ICD} 7^{\text {th }}(\%)$ & 7.47 & 4.47 \\
\hline K-Factor $(\%)$ & 7.32 & 1.12 \\
\hline
\end{tabular}

These results confirm that the voltage harmonics generated by nonlinear loads such as PWM motor drives, affects the whole network and the PCC. Meanwhile, the parameters of current harmonics depend mainly of nonlinear loads present in the circuit that generates those harmonics. Results also demonstrate that in this case study, it is necessary to take actions such as the installation of active filters to mitigate harmonics generated by PWM motor driver, mainly the fifth and seventh harmonics order.

\section{CONCLUSION}

The investigations carried out so far and the results of this work demonstrate that although there are standards establishing the allowable level of harmonics in the network and have been developed new technology for its mitigation, harmonic distortion in electrical networks generated by PWM motor drives remain an ongoing problem.

The analysis of harmonics in industrial electrical systems should be performed taking into account various parameters of harmonic distortion and not only one. In the case study analysed, it was observed that the THDV was below the established limits by IEEE Std 1159-2009. However, the THDI, IVD, ICD and KFactor, revealed the existence of harmonic problems that causing damages on electrical devices.

\section{REFERENCES}

[1] S. R. Movahed, et al., "Estimation of insulation life of inverter-fed induction motors," in Proceedings Conference Power Electronic \& Drive Systems \& Technologies Conference (PEDSTC), pp. 335-339, 2010.

[2] G. K. Singh, "A research survey of induction motor operation with non-sinusoidal supply wave forms," Electric Power Systems Research, vol/issue: 75(2), pp. 200-213, 2005. 
[3] G. Suresh, et al., "Analysis of the effect of feeder cable on the stator winding voltage stress in a PWM induction motor drive," in Proceedings Electrical Insulation Conference, 1997, and Electrical Manufacturing \& Coil Winding Conference, pp. 407-412, 1997.

[4] M. C. Di Piazza and M. Pucci. "Techniques for efficiency improvement in PWM motor drives," Electric Power Systems Research, vol. 136, pp. 270-280, 2016.

[5] M. Chirindo, et al., "Considerations for nonintrusive efficiency estimation of inverter-fed induction motors," IEEE Transactions on Industrial Electronics, vol/issue: 63(2), pp. 741-749, 2016.

[6] C. J. R. Kriel, et al., "The influence of variable speed drives on electric motor opperating temperatures," in Proceedings Industrial and Commercial Use of Energy Conference (ICUE), pp. 1-6, 2013.

[7] R. Mayuri, et al., "Eddy current loss modelling in transformer iron losses operated by PWM inverter," in Proceedings. Power Electronics, Drives and Energy Systems (PEDES) \& 2010 Power India, 2010 Joint International on, pp. 1-5, 2010.

[8] M. Digalovski, et al., "Impact of current high order harmonic to core losses of three-phase distribution transformer," in Proceedings. EUROCON, pp. 1531-1535, 2013.

[9] H. Oraee, "A quantative approach to estimate the life expectancy of motor insulation systems," IEEE Transactions on Dielectrics and Electrical Insulation, vol/issue: 7(6), pp. 790-796, 2000.

[10] A. Inan and F. Attar, "The life expectancy analysis for an electric motor due to harmonics," in Proceedings Electrotechnical Conference, MELECON 98, vol. 2, pp. 997-999, 1998.

[11] J. P. G. de Abreu and A. E. Emanuel, "Induction motor thermal aging caused by voltage distortion and imbalance: loss of useful life and its estimated cost," in Proceedings Industrial and Commercial Power Systems Technical Conference, pp. 105-114, 2001.

[12] V. S. Santos, et al., "Procedure for determining induction motor efficiency working under distorted grid voltages," IEEE Transaction on Energy Conversion, vol/issue: 30(1), pp. 331-339, 2015.

[13] P. Donolo, et al., "Voltage unbalance and harmonic distortion effects on induction motor power, torque and vibrations," Electric Power Systems Research, vol/issue: 140(1), pp. 866-873, 2016.

[14] "IEEE Recommended Practice for Monitoring Electric Power Quality,” IEEE Standard 1159, 2009.

[15] Y. Wang, et al., "Calculation of high frequency bearing currents of PWM inverter-fed VF induction motor," in Proceedings 2014 International Power Electronics and Application Conference and Exposition, Shanghai, pp. 1428-1433, 2014.

[16] Y. Wang, et al., "Research on discharging bearing currents of PWM inverter-fed variable frequency induction motor," in Proceedings Electrical Machines and Systems (ICEMS), pp. 2945-2949, 2014.

[17] B. Zhu, et al., "Effects of the inverter parameters on the eddy current losses in induction motor fed by PWM inverter," in Proceedings Electrical Machines and Systems ICEMS 2008, pp. 4240-4243, 2008

[18] A. Strandt, et al., "No-load power losses and motor overheating effects versus PWM switching frequencies," in Proceedings Renewable Energy Research and Application (ICRERA), pp. 280-283, 2014.

[19] D. M. Said, et al., "Analysis of distribution transformer losses and life expectancy using measured harmonic data," in Proceedings 14th International Conference on Harmonics and Quality of Power - ICHQP 2010, pp. 1-6, 2010.

[20] G. W. Massey, "Estimation methods for power system harmonic effects on power distribution transformers," IEEE Transactions on Industry Applications, vol/issue: 30(2), pp. 485-489, 1994.

[21] M. T. Bishop, et al., "Evaluating harmonic-induced transformer heating," IEEE Transactions on Power Delivery, vol/issue: 11(1), pp. 305-311, 1996.

[22] L. W. Pierce, "Transformer design and application considerations for nonsinusoidal load currents," IEEE Transactions on Industry Applications, vol/issue: 32(3), pp. 633-645, 1996.

[23] W. Chen and Z. Cheng, "An experimental study of the damaging effects of harmonics in power networks on the capacitor dielectrics," in Proceedings Second International Conference on Properties and Applications, vol. 2, pp. 645-648, 1988.

[24] C. Boonseng, et al., "Failure analysis of dielectric of low voltage power capacitors due to related harmonic resonance effects," in Proceedings Power Engineering Society Winter Meeting, 2001. IEEE, Columbus, vol. 3, pp. 1003-1008, 2001.

[25] A. Souli and A. Hellal, "Design of a Computer Code To Evaluate the Influence of the Harmonics in the Electrical Networks," International Journal of Electrical and Computer Engineering, vol/issue: 2(5), pp. 681-690, 2012.

[26] M. J. H. Rawa, et al., "Power quality monitoring and simulation of a personal computer based on IEEE 14592010," in Proceedings International Symposium on Electromagnetic Compatibility, pp. 671-675, 2013.

[27] P. Aramwanid and I. Boonyaroonate, "Power quality impact study and analysis of electrical power efficacy in sugar industry," in Proceedings Conference Electrical Engineering/Electronics, Computer, Telecommunications and Information Technology, pp. 1-4, 2015.

[28] M. J. Ghorbani and H. Mokhtari, "Impact of Harmonics on Power Quality and Losses in Power Distribution Systems," International Journal of Electrical and Computer Engineering, vol/issue: 5(1), pp. 166-174, 2015.

[29] Y. Baghzouz, et al., "Time-varying harmonics. I. Characterizing measured data," IEEE Transactions on Power Delivery, vol/issue: 13(3), pp. 938-944, 1998.

[30] A. E. Emanuel and J. A. Orr, "Six-pulse converter atypical harmonics caused by second harmonic voltage," in Proceedings Conference 10th International Conference on Harmonics and Quality of Power, pp. 340-346, 2002.

[31] C. Collombet, et al., "Harmonics disturbances in networks, and their treatment," Cahier Technique Merlin Gerin, vol/issue: 1(152), pp. 1-31, 1999. 


\section{BIOGRAPHIES OF AUTHORS}
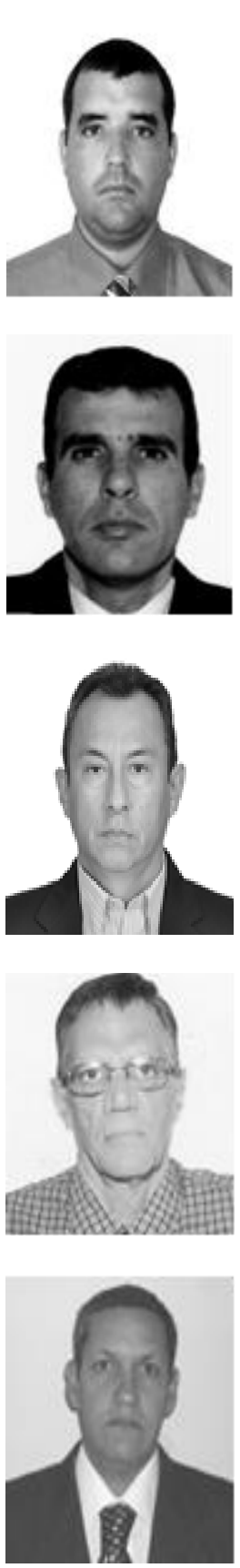

Vladimir Sousa Santos was born in Cienfuegos, Cuba on November 21, 1980. Received the B.S degree in Electrical Engineering from Universidad Central de Las Villas, Santa Clara. Cuba, in 2004. Received the M.Sc. degree in Energy Efficiency from the Universidad de Cienfuegos, Cuba in 2006. Received the Dr.C. (Ph.D.) degree from the Universidad Central de Las Villas, Santa Clara, Cuba, in 2014. Currently is with GIOPEN of the Faculty of Engineering of Universidad de la Costa (CUC). Barranquilla. Colombia. His area of interest includes electric machines, power quality and energy efficiency.

Hernan Hernández Herrera was born in Cienfuegos, Cuba on July 7, 1976. Received the B.S degree in Mechanical Engineering from the Universidad de Cienfuegos, Cuba in 2000. M. Sc. in applied mechanics from the Universidad de Cienfuegos, Cuba 2005. Received the Dr.C. (Ph.D.) degree from the Universidad de Cienfuegos, Cuba, in 2006. Currently is with GIOPEN of the Faculty of Engineering of Universidad de la Costa (CUC). Barranquilla. Colombia. His area of interest includes applied mechanics and energy efficiency.

Enrique C. Quispe (M'95. SM'12) was born in Lima, Perú, on January 20, 1956. He received the B.Sc. in Electrical Engineering from the Universidad Nacional de Ingeniería, Perú in 1980. M.Sc. in Electrical Engineering. M. Eng. in Industrial Automation and PhD. in Electrical Engineering from Universidad del Valle, Colombia in 1994, 1997 and 2011, respectively. Since 1992, he has been with Universidad Autónoma de Occidente, Cali, Colombia, where he is currently a Professor in the Department of Energy and Mechanics and the Director of the Energy Research Group. His current research interests include the analysis of electrical machines and drives, power quality and management and energy efficiency. He is an IEEE Senior Member.

Percy R. Viego Felipe was born in Cienfuegos, Cuba on November 19, 1944. Received the B.S. degree in Electrical Engineering from the Universidad Central de Las Villas, Santa Clara, Cuba, in 1965. Received the Dr.C. (Ph.D.) degree from the Central Universidad Participated in a postdoctoral scholarship on single-phase induction machine design at the Lappeenranta University of Technology, Finland, in 1994. Currently is with the Center of Energy and Environmental Studies (CEEMA), Faculty of Engineering, Universidad de Cienfuegos, Cuba

Julio R. Gómez Sarduy was born in 1963 in Cienfuegos, Cuba. Received the B.S degree in electrical engineering from Universidad Central de Las Villas, Santa Clara, Cuba, in 1986. Received the M.Sc. degree in electrical engineering from Universidad Central de Las Villas, Santa Clara, Cuba, in 1996, from there he received his Ph.D. degree in 2006. Currently is with the Center for the Study of Energy and Environment (CEEMA). Faculty of Engineering, Universidad de Cienfuegos, Cienfuegos, Cuba. His area of interest includes electric machines, power quality and energy efficiency in industrial power systems. 